\title{
Doenças pós-colheita em citros e caracterização da população fúngica ambiental no mercado atacadista de São Paulo
}

\author{
Ivan. H. Fischer ${ }^{1}$, Silvia A. Lourenço ${ }^{2}$ \& Lilian Amorim² \\ ${ }^{1}$ Agência Paulista de Tecnologia dos Agronegócios, Av. Rodrigues Alves 40-40, 17030-000, Bauru, SP, Brasil; ${ }^{2}$ Departamento \\ de Entomologia, Fitopatologia e Zoologia Agrícola, ESALQ, Universidade de São Paulo, Cx. Postal 9, 13418-900, Piracicaba, \\ SP, Brasil
}

Autor para correspondência: Ivan Herman Fischer, e-mail: ihfische@apta.sp.gov.br

\begin{abstract}
RESUMO
Este trabalho objetivou caracterizar os danos pós-colheita e as características físico-químicas de frutos de laranjas 'Pêra' e 'Lima' e de tangor 'Murcott' comercializados na Ceagesp SP, bem como caracterizar a micoflora ambiental nos pontos de revenda de citros da Ceagesp, em 2006. Frutos cítricos foram coletados de atacadistas e armazenados durante 14 dias a $25^{\circ} \mathrm{C}$ e $85-90 \%$ de UR. A incidência de injúrias foi avaliada visualmente a cada três dias. As variáveis físico-químicas analisadas foram acidez titulável e teor de sólidos solúveis. A micoflora ambiental foi amostrada mediante o método gravimétrico, com placas de Petri, contendo meio batata-dextrose-ágar+pentabiótico, abertas por dois minutos. A incidência de podridões em laranjas 'Pêra' e 'Lima' e tangor 'Murcott' atingiu valores médios de 12,8; 14,9 e $25,8 \%$, respectivamente, ao final do armazenamento, sendo o bolor verde a principal doença pós-colheita. Associações entre os parâmetros físico-químicos de maturação e a incidência de podridões foram, em geral, não significativas. A população fúngica ambiental variou significativamente entre os meses amostrados, com média de 25,3 ufc/placa e os gêneros Penicillium e Cladosporium foram os mais abundantes. Observou-se correlação positiva $(\mathrm{r}=0,96)$ entre a freqüência de $P$. digitatum encontrada no ambiente dos atacadistas e o bolor verde em laranja 'Pêra' comercializada. Entretanto, para laranja 'Lima' e tangor 'Murcott' tal correlação não foi verificada.
\end{abstract}

Palavras chaves: Citrus; doenças fúngicas; Penicillium digitatum

\begin{abstract}
Postharvest diseases in citrus and characterization of the fungal population in São Paulo's wholesale market

The purposes of this work were to characterize postharvest injuries and to evaluate the physicochemical characteristics of 'Pêra' and 'Lima' oranges and 'Murcott' tangor at Ceagesp market, as well as to characterize the environmental mycoflora in retail points at Ceagesp in 2006. Fruits collected at retail points were stored for 14 days at $25^{\circ} \mathrm{C}$ and $85-90 \% \mathrm{RH}$. The incidence of injuries was visually evaluated every three days. The physicochemical characteristics analyzed were titratable acidity and soluble solids amount. The environmental mycoflora was sampled according to the gravimetric method, using Petri dishes containing potato-dextrose-agar medium+pentabiotic opened for two minutes. The average rot incidences in 'Pêra' and 'Lima' oranges and 'Murcott' tangor were 12.8, 14.9 and 25.8\%, respectively, at the end of the storage period, and green mold was the main postharvest disease. Associations between physicochemical parameters and rot incidence was, in general, not significant. The environmental fungal population varied significantly between the sampling months in retail points with an average of $25.3 \mathrm{cfu} /$ plate. Penicillium and Cladosporium were the most recorded genera of fungi. Positive correlation (r=0.96) was observed between frequency of $P$. digitatum found in the environment of retail points and the green mold in on-sale fruits of 'Pêra' orange. However, for 'Lima' orange and 'Murcott' tangor such a correlation was not verified.
\end{abstract}

Keywords: Citrus, fungal diseases, Penicillium digitatum.

\section{INTRODUÇÃO}

As podridões constituem-se na principal causa de danos pós-colheita em citros e se expressam desde a colheita até seu uso pelo consumidor. A porcentagem de frutos cítricos com podridões que ocorrem em uma safra varia

Parte da Tese de Doutorado do primeiro autor. ESALQ, Universidade de São Paulo. Piracicaba SP. 2007. de 3 a 6\% (Palou et al., 2001b), entretanto, sob condições favoráveis aos fitopatógenos perdas consideráveis em pós-colheita podem ocorrer, atingindo $50 \%$ no período de comercialização de laranja (Eckert, 1993). Levantamento da incidência de doenças pós-colheita em laranja 'Pêra' comercializada na Central de Abastecimento de Recife detectou incidência de $22 \%$ de podridões fúngicas após cinco dias de armazenamento dos frutos em condições de temperatura ambiente (Dantas et al., 2003).

$\mathrm{O}$ bolor verde [Penicillium digitatum (Pers.:Fr.) Sacc.] é considerado a principal doença pós-colheita dos citros e está disseminado em todos os países produtores, 
afetando todas as espécies e variedades cítricas (Eckert \& Eaks, 1989). Provoca uma podridão mole no fruto, recobrindo-o com micélio branco e grande número de esporos, os quais the dão uma coloração verde. A ocorrência da doença depende muito das condições climáticas e da forma de manipulação dos frutos, desde o pomar até o consumidor, já que a infecção ocorre mediante ferimentos na casca do fruto (Laranjeira et al., 2005). Outras doenças, como as podridões pedunculares [Lasiodiplodia theobromae (Pat.) Griffon \& Maubl. e Phomopsis citri Fawcett], a antracnose [Colletotrichum gloeosporioides (Penz.) Sacc.], o bolor azul $P$. italicum Wehmer), podem ser importantes sob determinadas condições.

Vários fatores relacionados com o fruto, o patógeno, o clima e as condições em pós-colheita determinam a incidência e a severidade das doenças (Eckert \& Eaks, 1989). Entre estes, a quantidade e a qualidade do inóculo fúngico ocupam um lugar de destaque. A probabilidade de infecção depende da quantidade de inóculo presente em um ponto do fruto suscetível. Esta relação foi demonstrada para patógenos importantes como P. digitatum (Wild \& Eckert, 1982), Geotrichum candidum (Baudoin \& Eckert, 1982) e C. gloeosporioides (Brown, 1975), segundo a qual, a quantidade de esporos presentes nos packinghouses de citros influi decisivamente nos níveis de podridão, especialmente nas provocadas por patógenos que penetram por ferimento, como os bolores (Eckert \& Eaks, 1989). Estudar a população fúngica de uma região citrícola é importante para se determinar a presença de fitopatógenos e sua distribuição, visando estabelecer riscos potenciais de danos aos frutos e planejar adequadamente os métodos de controle.

O grau de maturação da fruta na colheita também é importante, pois condiciona a qualidade pós-colheita. Frutas cítricas colhidas muito maduras apresentam pouca firmeza, maior suscetibilidade a injúrias mecânicas, podridões, alterações fisiológicas e possuem uma menor vida de prateleria (Pereira et al., 2006). Diversos estudos com frutíferas têm relacionado o grau de maturação a períodos de maior ou menor suscetibilidade às podridões (Sharma \& Kaul, 1988; Mari et al., 2003; Northover \& Biggs, 1990). No entanto, não se sabe ao certo, o papel das características físico-químicas dos frutos cítricos condicionando maior ou menor suscetibilidade às podridões.

A caracterização dos danos visa facilitar a tomada de decisão quanto à necessidade de investimento em medidas de prevenção. Os objetivos deste trabalho foram: a) caracterizar as injúrias e quantificar os danos pós-colheita em laranja doce Citrus sinensis Osbeck 'Pêra' e 'Lima' e de tangor 'Murcott' (C. sinensis x C. reticulata) comercializados na Companhia de Entrepostos e Armazéns Gerais de São Paulo (Ceagesp); b) correlacionar a incidência de podridões com as características físico-químicas sólidos solúveis e acidez (\%) dos frutos; e c) caracterizar a micoflora ambiental nos atacadistas que comercializam frutos cítricos na Ceagesp e relacioná-la a incidência de podridões pós-colheita.

\section{MATERIAL E MÉTODOS}

A terminologia de Zadoks (1985) foi adotada neste trabalho. Qualquer sintoma visual mensurável causado por agentes biológicos nocivos ou impactos mecânicos é denominado injúria; dano é a redução em quantidade e/ou qualidade do fruto e perda a redução financeira decorrente do dano. No entanto, em doenças pós-colheita que afetam todo o fruto, os termos injúria e dano muitas vezes são sinônimos, pois a incidência de injúria coincide com a redução em qualidade ou quantidade comercializada. Assim, o termo dano foi adotado, preferencialmente, sempre que essa generalização não comprometesse seu significado.

As amostragens das laranjas 'Pêra' e 'Lima' (maio a novembro) e de tangor 'Murcott' (agosto a novembro) comercializados na Ceagesp e da micoflora ambiental dos atacadistas (maio a outubro) foram realizadas mensalmente em 2006. A incubação, identificação e quantificação dos danos pós-colheita e da micoflora ambiental foram realizados no Laboratório de Epidemiologia, Setor de Fitopatologia, da Escola Superior de Agricultura "Luiz de Queiroz", Universidade de São Paulo, Piracicaba, SP.

\section{Caracterização dos danos pós-colheita em citros}

As amostragens foram realizadas em quatro atacadistas que comercializavam frutos cítricos, perfazendo 50 frutos de cada variedade por atacadista e totalizando 200 frutos para cada variedade. Um total de 3600 frutos foi avaliado no período do levantamento. Considerando que parte dos atacadistas da Ceagesp comercializava frutos tratados com os fungicidas tiabendazol ou imazalil, em pós-colheita, optou-se por atacadistas que sabidamente comercializavam frutos sem tratamento fungicida pós-colheita.

Os frutos foram individualizados em bandejas plásticas e submetidos à câmara úmida por 24 horas, visando favorecer a ocorrência de podridões, permanecendo por mais 13 dias em câmara com temperatura e umidade relativa controladas, a $25^{\circ} \mathrm{C}$ e $85-90 \%$ de UR. A incidência de injúrias foi avaliada visualmente após a retirada da câmara úmida e a cada três dias. Os fungos isolados de frutos podres tiveram a patogenicidade confirmada através da inoculação em frutos sadios.

Compararam-se as incidências das podridões nos meses amostrados por meio de teste não paramétrico de comparação de múltiplas proporções, em nível de 5\% de probabilidade (Zar, 1999). A incidência de danos mecânicos de oleocelose e lesões não cicatrizadas foi correlacionada com a incidência de bolor verde nas diferentes amostragens na Ceagesp. Foram testadas correlações simples.

\section{Análises físico-químicas dos frutos cítricos}

As análises físico-químicas dos frutos foram realizadas no Laboratório de Pós-Colheita do Setor de Horticultura da ESALQ/USP. Dez frutos de cada amostragem nos quatro atacadistas, em adição aos 50 frutos destinados à caracterização dos danos pós-colheita, foram utilizados para 
a obtenção de uma amostra composta de suco cítrico. Foram determinados dois parâmetros:

a) Teor de sólidos solúveis - Apresenta uma indicação inicial do teor de açúcares no fruto. Foi medido por meio de leitura direta em refratômetro digital com correção automática de temperatura (Atago PR-101, Atago Co Ltda., Tókio, Japão) sendo os resultados expressos em ${ }^{\circ}$ Brix. Foram feitas duas leituras, considerando-se a média das leituras.

b) Acidez titulável - Para essa determinação, $10 \mathrm{~g}$ de polpa foram diluídas em $90 \mathrm{~mL}$ de água destilada. A titulação foi feita com hidróxido de sódio $(0,1 \mathrm{~N})$ até que a solução atingisse $\mathrm{pH} \mathrm{8,1} \mathrm{(ponto} \mathrm{de} \mathrm{virada} \mathrm{da} \mathrm{fenolftaleína).} \mathrm{Os}$ cálculos foram realizados segundo Carvalho et al. (1990) e os resultados expressos em acidez (\%).

As variáveis físico-químicas foram correlacionadas com a incidência de bolor verde e total de doenças póscolheita em todas as datas de amostragem. Foram testadas correlações simples, posteriormente analisadas pelo teste $\mathrm{F}$ $(P<0,05)$.

\section{Caracterização da micoflora da Ceagesp}

A micoflora ambiental foi amostrada mediante o método gravimétrico em quatro atacadistas que comercializavam frutos cítricos, escolhidos aleatoriamente. Cinco placas de Petri de $9 \mathrm{~cm}$ de diâmetro (repetições) com meio batata-dextrose-ágar acrescido ao meio fundente de $0,4 \mathrm{~g} / \mathrm{L}$ de pentabiótico veterinário (Fort Dodge ${ }^{\circledR}$ ) foram distribuídas, sempre que possível, uma em cada extremidade e uma no centro do Box de comercialização atacadista, e abertas por dois minutos para que os esporos fúngicos depositassem por gravidade sobre o meio de cultivo.

As placas foram incubadas a $20^{\circ} \mathrm{C}$ e fotoperíodo de $12 \mathrm{~h}$, durante cinco a sete dias, transcorridos os quais procedeu-se a contagem e identificação das colônias fúngicas. A identificação foi feita em nível de gênero, exceto para a espécie $P$. digitatum, e quando necessário, realizouse mediante observação microscópica. A freqüência de cada gênero fúngico foi expressa como número de unidades formadoras de colônias por placa (ufc/placa).

\section{RESULTADOS E DISCUSSÃO}

\section{Doenças pós-colheita de frutos cítricos}

Os frutos de laranjas 'Pêra' e 'Lima' e de tangor 'Murcott' apresentaram incidência de diferentes doenças fúngicas pós-colheita, atingindo médias de 4,5; 7,8 e 11,6\% aos sete dias de armazenamento e 12,$8 ; 14,9$ e $25,8 \%$ aos 14 dias de armazenamento, respectivamente. Foram verificadas diferenças significativas na incidência de doenças $(P<0,05)$ entre os períodos de coleta de frutos (Tabelas 1-3).

Entre as doenças detectadas em frutos cítricos o bolor verde apresentou as maiores médias de incidências (5,6$14,6 \%$ ), diferindo significativamente das demais doenças em laranja 'Lima' e tangor 'Murcott'. Em regiões semi-áridas, o bolor verde é considerado a mais importante doença póscolheita em laranjas e tangerinas, podendo, em adição ao bolor azul, representar mais de $90 \%$ do total de danos, durante as fases de transporte, armazenamento e comercialização (Eckert \& Eaks, 1989). A elevada incidência da doença pode ser atribuída à elevada produção de esporos na superfície dos frutos, facilmente dispersos pelo ar, sendo abundantes nos pomares e nos packinghouses, principalmente nos locais de viragem das caixas. Potencialmente, um único esporo de $P$. digitatum pode infectar um fruto e resultar na produção de 100 milhões de esporos, após sete dias sob condições ambientais ótimas (Timmer et al., 2000).

A podridão peduncular de Lasiodiplodia apresentou a segunda maior incidência em laranjas 'Pêra' $(4,0 \%)$ e 'Lima' $(1,9 \%)$, sendo estatisticamente semelhante ao bolor verde em laranja 'Pêra', e a terceira posição em tangor 'Murcott'

TABELA 1 - Incidência (\%) de doenças fúngicas pós-colheita em laranja 'Pêra' comercializada em 2006 na Ceagesp-SP, aos 14 dias de armazenamento

\begin{tabular}{lllllllll}
\hline \hline \multirow{2}{*}{ Doenças } & \multicolumn{7}{c}{ Amostragens $^{2}$} \\
\cline { 2 - 8 } & Maio & Junho & Julho & Agosto & Setembro & Outubro & Novembro & Média \\
\hline Bolor verde & $5,0 \mathrm{aAB}$ & $2,7 \mathrm{aA}$ & $4,5 \mathrm{aA}$ & $5,5 \mathrm{aA}$ & $2,5 \mathrm{aAB}$ & $2,0 \mathrm{aAB}$ & $17,0 \mathrm{bA}$ & $5,6 \mathrm{~A}$ \\
Antracnose & $0,7 \mathrm{aBC}$ & $0,0 \mathrm{aAB}$ & $1,0 \mathrm{aAB}$ & $0,5 \mathrm{aBC}$ & $0,5 \mathrm{aB}$ & $0,0 \mathrm{aB}$ & $2,5 \mathrm{aB}$ & $0,7 \mathrm{BC}$ \\
Podr. de Fusarium & $0,0 \mathrm{aC}$ & $0,3 \mathrm{aAB}$ & $0,0 \mathrm{aB}$ & $0,0 \mathrm{aC}$ & $0,5 \mathrm{aB}$ & $0,5 \mathrm{aAB}$ & $0,0 \mathrm{aB}$ & $0,2 \mathrm{BC}$ \\
Podr. de Phomopsis & $3,0 \mathrm{aBC}$ & $0,3 \mathrm{abAB}$ & $0,0 \mathrm{bB}$ & $0,0 \mathrm{bC}$ & $1,0 \mathrm{abB}$ & $1,0 \mathrm{abAB}$ & $1,5 \mathrm{abB}$ & $1,0 \mathrm{ABC}$ \\
Podr. de Lasiodiplodia & $13,0 \mathrm{aAB}$ & $0,3 \mathrm{cdAB}$ & $2,0 \mathrm{bcdAB}$ & $3,5 \mathrm{bcAB}$ & $6,5 \mathrm{abA}$ & $2,5 \mathrm{bcdAB}$ & $0,0 \mathrm{~dB}$ & $4,0 \mathrm{AB}$ \\
Bolor azul & $0,3 \mathrm{abC}$ & $0,3 \mathrm{abAB}$ & $0,0 \mathrm{bB}$ & $0,0 \mathrm{bC}$ & $1,0 \mathrm{abB}$ & $3,0 \mathrm{aA}$ & $0,0 \mathrm{bB}$ & $0,7 \mathrm{BC}$ \\
Podridão azeda & $0,3 \mathrm{abC}$ & $0,0 \mathrm{bB}$ & $0,0 \mathrm{bB}$ & $0,0 \mathrm{bC}$ & $0,5 \mathrm{abB}$ & $3,0 \mathrm{aA}$ & $0,0 \mathrm{bB}$ & $0,5 \mathrm{BC}$ \\
Podridão negra & $0,0 \mathrm{aC}$ & $0,0 \mathrm{aB}$ & $0,0 \mathrm{aB}$ & $0,0 \mathrm{aC}$ & $1,0 \mathrm{aB}$ & $0,0 \mathrm{aB}$ & $0,0 \mathrm{aB}$ & $0,1 \mathrm{C}$ \\
Total & $22,3 \mathrm{a}$ & $4,0 \mathrm{c}$ & $7,5 \mathrm{bc}$ & $9,5 \mathrm{bc}$ & $13,5 \mathrm{ab}$ & $12,0 \mathrm{ab}$ & $21,0 \mathrm{a}$ & 12,8 \\
\hline & & & & & & &
\end{tabular}


(2,8\%). É uma importante doença em regiões quentes e úmidas, como na Florida e Caribe (Timmer et al., 2000). Em Recife, a podridão peduncular de Lasiodiplodia foi a principal doença em laranja 'Pêra' com 11,8\% de incidência (Dantas et al., 2003). Essa elevada incidência pode ser atribuída à temperatura do local de armazenamento dos frutos, em torno de $30^{\circ} \mathrm{C}$, aliada ao uso do etileno para o desverdecimento dos frutos, que causa a abscisão precoce do cálice, facilitando a entrada do patógeno que se encontra latente nos tecidos necróticos do cálice (Barmore \& Brown, 1985). Segundo Ismail \& Zhang (2004) a doença desenvolvese rapidamente durante e após excessivo desverdecimento e pode ser observada no packinghouse, sendo mais freqüente sua observação na chegada ao mercado ou logo depois.

A podridão azeda (Geotrichum candidum) apresentou a segunda maior incidência em tangor 'Murcott' $(3,6 \%)$ e valores médios de $0,5 \%$ e $0,3 \%$ em laranjas 'Pêra' e 'Lima', respectivamente. Afeta principalmente frutos maduros ou em avançado estádio de maturação, localizados próximos ao solo, já que o agente causal é um saprófita habitante do solo e que, por efeito da chuva, atinge os frutos (Laranjeira et al., 2005). Os frutos doentes exalam um forte e desagradável odor ácido e pútrido, sendo considerada a mais desagradável doença pós-colheita em citros (Timmer et al., 2000). A podridão azeda foi relatada por Eckert (1993) como a segunda doença pós-colheita dos citros em importância, após os bolores, com infecção por ferimentos, e um dos mais sérios problemas para a indústria de limão na Califórnia (Eckert \& Eaks, 1989). A sua maior ocorrência, assim como para os bolores, em tangor 'Murcott' (Tabela 3) quando comparado às laranjas (Tabelas 1-2), deve estar associada às lesões não cicatrizadas que foram superiores em tangor (Figura 1). Segundo Pio et al. (2005), as tangerinas e seus híbridos são muito sensíveis às injúrias decorrentes do manuseio na colheita, pós-colheita e transporte e que servem de porta de entrada aos patógenos.

Os resultados obtidos confirmam a importância econômica das podridões pós-colheita em citros, uma vez que essas doenças desqualificam a fruta para comercialização pela simples presença dos sintomas, como destacado por Eckert (1993), que mencionou perdas de até 50\% durante o período de comercialização. Assim, a grande diversidade de doenças pós-colheita provenientes de infecções latentes e/ou ativas constatada sugere a necessidade do emprego de medidas de controle mais efetivas durante as fases de produção e pós-colheita. Boas práticas agrícolas, incluindo adequada fertilização, controle de pragas, podas de limpeza e remoção de frutos caídos no pomar, reduzem os tecidos vegetais mortos e conseqüentemente a fonte de inóculo de patógenos, como C. gloeosporioides, L. theobromae, P. citri, A. alternata e Penicillium spp. Infecções em pós-colheita podem ser reduzidas através do manuseio cuidadoso dos frutos durante as operações de colheita, transporte, processamento e armazenamento; da utilização de drencher para a limpeza dos frutos antes de entrarem no packinghouse; da higienização, com produtos a base de cloro e amônia quaternária, das caixas de colheita e instalações (máquinas, câmaras, piso, etc.) do packinghouse. Aplicações de tiofanato metílico e benomil em pré-colheita reduziram pela metade a incidência de podridões em frutos cítricos, após o armazenamento (Ritenour et al., 2004). Do mesmo modo, redução de podridões pode ser obtida pelo emprego dos fungicidas tiabendazol e imazalil em pós-colheita. Estima-se que sem o uso de tiabendazol em pós-colheita na Flórida, a venda de frutos cítricos poderia sofrer redução de até 50\% (Ismail \& Zhang, 2004). A regulação do ambiente pelo uso de câmaras frias no armazenamento e contêineres refrigerados no transporte dos frutos beneficiados atrasa consideravelmente o desenvolvimento das podridões, sendo prática importante, especialmente se combinada com o tratamento químico, para a redução das doenças em póscolheita.

\section{Injúrias em frutos cítricos}

A injúria mecânica de oleocelose e frutos desidratados foram superiores em laranja 'Lima', seguido por laranja 'Pêra' e tangor 'Murcott'. Lesões não cicatrizadas foram superiores em tangor 'Murcott', seguido por laranjas 'Lima' e 'Pêra' (Figura 1). Embora o tecido danificado torne-se susceptível à infecção por microrganismos patogênicos (Laranjeira et $a l ., 2005)$ não foram observadas correlações $(P>0,05)$ entre a incidência de injúrias mecânicas de oleocelose e de lesões não cicatrizadas com a incidência de bolor verde em frutos cítricos nos diferentes meses amostrados.

\section{Relação entre parâmetros físico-químicos e incidência de podridões}

Os parâmetros físico-químicos ${ }^{\circ}$ Brix e acidez (\%) dos frutos cítricos e suas correlações com a incidência de bolor verde e o total de podridões estão expressos na Tabela 4. Correlações negativas entre ${ }^{\circ}$ Brix e a incidência de bolor verde e o total de podridões foram observadas em laranja 'Lima'. Nas demais variedades cítricas não foram observadas correlações significativas entre os parâmetros físico-químicos avaliados e a incidência de doenças póscolheita.

Embora associações entre o aumento das infecções com a elevação da concentração de sólidos solúveis ou a diminuição da acidez tenham sido relatadas em frutos de cereja (Northover \& Biggs, 1990), maçã (Sharma \& Kaul, 1988) e pêssego (Souza, 2007), essas características não auxiliaram no entendimento das causas de resistência/ suscetibilidade dos frutos cítricos, devendo ser consideradas apenas no planejamento da colheita. Segundo Medina et al. (2005), os frutos cítricos são não climatéricos e durante a sua maturação, não ocorrem variações drásticas na composição química, não apresentando um ponto definido de maturação.

\section{População fúngica em ambiente de atacadistas de citros}

O numero médio de colônias fúngicas, por placa de Petri, isoladas do ambiente dos atacadistas que 
TABELA 2 - Incidência (\%) de doenças fúngicas pós-colheita em laranja 'Lima' comercializada em 2006 na Ceagesp-SP, aos 14 dias de armazenamento

\begin{tabular}{lllllllll}
\hline \hline Doenças & \multicolumn{7}{c}{ Amostragens $^{2}$} \\
\cline { 2 - 8 } & Maio & Junho & Julho & Agosto & Setembro & Outubro & Novembro & Média \\
\hline Bolor verde & $9,3 \mathrm{bcdaA}$ & $11,0 \mathrm{bcA}$ & $12,0 \mathrm{bcA}$ & $23,5 \mathrm{aA}$ & $3,0 \mathrm{dAB}$ & $7,0 \mathrm{bcdA}$ & $4,0 \mathrm{cdA}$ & $10,0 \mathrm{~A}$ \\
Antracnose & $0,0 \mathrm{aC}$ & $1,0 \mathrm{aB}$ & $0,0 \mathrm{aB}$ & $0,5 \mathrm{aB}$ & $0,5 \mathrm{aB}$ & $1,0 \mathrm{aB}$ & $2,5 \mathrm{aAB}$ & $0,8 \mathrm{~B}$ \\
Podr. de Fusarium & $0,0 \mathrm{aC}$ & $0,0 \mathrm{aB}$ & $0,0 \mathrm{aB}$ & $0,0 \mathrm{aB}$ & $1,5 \mathrm{aAB}$ & $1,5 \mathrm{aAB}$ & $0,5 \mathrm{aAB}$ & $0,5 \mathrm{~B}$ \\
Podr. de Phomopsis & $2,0 \mathrm{aBC}$ & $1,0 \mathrm{aB}$ & $2,5 \mathrm{aB}$ & $0,5 \mathrm{aB}$ & $1,0 \mathrm{aAB}$ & $0,0 \mathrm{aB}$ & $0,5 \mathrm{aAB}$ & $1,1 \mathrm{~B}$ \\
Podr. de Lasiodiplodia & $7,3 \mathrm{aAB}$ & $0,7 \mathrm{bcB}$ & $0,5 \mathrm{bcB}$ & $0,0 \mathrm{cB}$ & $5,0 \mathrm{abA}$ & $0,0 \mathrm{cB}$ & $0,0 \mathrm{cB}$ & $1,9 \mathrm{~B}$ \\
Bolor azul & $0,0 \mathrm{aC}$ & $0,3 \mathrm{aB}$ & $0,0 \mathrm{aB}$ & $0,5 \mathrm{aB}$ & $0,5 \mathrm{aB}$ & $0,0 \mathrm{aB}$ & $0,0 \mathrm{aB}$ & $0,2 \mathrm{~B}$ \\
Podridão azeda & $0,0 \mathrm{aC}$ & $0,0 \mathrm{aB}$ & $0,5 \mathrm{aB}$ & $0,0 \mathrm{aB}$ & $0,5 \mathrm{aB}$ & $0,5 \mathrm{aB}$ & $0,5 \mathrm{aB}$ & $0,3 \mathrm{~B}$ \\
Podridão negra & $0,0 \mathrm{aC}$ & $0,3 \mathrm{aB}$ & $0,0 \mathrm{aB}$ & $0,5 \mathrm{aB}$ & $0,5 \mathrm{aB}$ & $0,0 \mathrm{aB}$ & $0,0 \mathrm{aB}$ & $0,2 \mathrm{~B}$ \\
Total & $18,7 \mathrm{ab}$ & $14,3 \mathrm{abc}$ & $15,5 \mathrm{abc}$ & $25,5 \mathrm{a}$ & $12,5 \mathrm{bc}$ & $10,0 \mathrm{bc}$ & $8,0 \mathrm{c}$ & 14,9 \\
\hline
\end{tabular}

${ }^{1}$ Dados seguidos pela mesma letra minúscula na linha e maiúscula na coluna, não diferem entre si, em nível de $5 \%$ pelo teste não paramétrico de comparação de múltiplas proporções.

2 Média de 200 frutos amostrados por mês.

TABELA 3 - Incidência (\%) de doenças fúngicas pós-colheita em tangor 'Murcott' comercializado em 2006 na CeagespSP, aos 14 dias de armazenamento

\begin{tabular}{lccccc}
\hline \hline \multirow{2}{*}{ Doenças } & \multicolumn{5}{c}{ Amostragens $^{2}$} \\
\cline { 2 - 6 } & Agosto & Setembro & Outubro & Novembro & Média \\
\hline Bolor verde & $16,0 \mathrm{abA}{ }^{1}$ & $11,5 \mathrm{bA}$ & $7,5 \mathrm{bA}$ & $23,5 \mathrm{aA}$ & $14,6 \mathrm{~A}$ \\
Antracnose & $0,7 \mathrm{aB}$ & $0,5 \mathrm{aC}$ & $1,0 \mathrm{aBC}$ & $2,0 \mathrm{aBC}$ & $1,0 \mathrm{~B}$ \\
Podridão de Fusarium & $0,0 \mathrm{aB}$ & $0,0 \mathrm{aC}$ & $0,5 \mathrm{aC}$ & $0,5 \mathrm{aC}$ & $0,3 \mathrm{~B}$ \\
Podridão de Phomopsis & $2,0 \mathrm{aB}$ & $1,5 \mathrm{aBC}$ & $2,0 \mathrm{aABC}$ & $2,0 \mathrm{aBC}$ & $1,9 \mathrm{~B}$ \\
Podridão de Lasiodiplodia & $2,7 \mathrm{abB}$ & $5,5 \mathrm{aAB}$ & $3,0 \mathrm{aABC}$ & $0,0 \mathrm{bC}$ & $2,8 \mathrm{~B}$ \\
Bolor azul & $0,0 \mathrm{bB}$ & $0,0 \mathrm{bC}$ & $4,0 \mathrm{aA}$ & $0,5 \mathrm{abC}$ & $1,1 \mathrm{~B}$ \\
Podridão azeda & $1,3 \mathrm{abB}$ & $0,0 \mathrm{bC}$ & $6,5 \mathrm{aA}$ & $6,5 \mathrm{aB}$ & $3,6 \mathrm{~B}$ \\
Podridão negra & $0,0 \mathrm{aB}$ & $0,5 \mathrm{aC}$ & $0,5 \mathrm{aC}$ & $0,0 \mathrm{aC}$ & $0,3 \mathrm{~B}$ \\
Podridão de Aspergillus & $0,0 \mathrm{aB}$ & $0,0 \mathrm{aC}$ & $0,0 \mathrm{aC}$ & $1,0 \mathrm{aC}$ & $0,3 \mathrm{~B}$ \\
Total & $22,7 \mathrm{~b}$ & $19,5 \mathrm{~b}$ & $25,0 \mathrm{ab}$ & $36,0 \mathrm{a}$ & 25,8 \\
\hline
\end{tabular}

comercializavam frutos cítricos foi de 25,3, estando dentro do intervalo (24,5-39,6 ufc/placa) encontrado em levantamento de três anos, em packinghouses citrícolas espanhóis (Palou et al., 2001b). Penicillium foi o gênero mais freqüente com $64,1 \%$ das colônias isoladas, sendo $13,4 \%$ da espécie $P$. digitatum, seguido por Cladosporium (15,7\%), Trichoderma (4,7\%), Fusarium (3,9\%), Rhizopus (2,0\%), Epicoccum (1,3\%), Alternaria (0,9\%) e os 7,3\% restantes pertencentes aos gêneros Aspergillus, Mucor, Aureobasidium, Geotrichum, Neurospora e outros (dados não apresentados).

Os resultados obtidos devem ser analisados levandose em consideração os métodos de amostragem utilizados. Diferenças de velocidade e características de crescimento entre os esporos coletados podem mascarar a presença de alguns gêneros fúngicos. $\mathrm{O}$ meio de cultivo empregado também pode favorecer o crescimento de alguns fungos em detrimento de outros (Palou et al., 2001b). Levantamentos da micoflora em pomares de tangerinas e packinghouses espanhóis indicaram o predomínio dos gêneros Cladosporium e Penicillium. Enquanto Cladosporium foi o gênero mais abundante no início da safra, com 55-60\% das colônias isoladas, a população de Penicillium spp. aumentou no decorrer da safra, chegando a superar a população de Cladosporium spp., com 40-65\% das colônias fúngicas isoladas, sugerindo segundo Palou et al. (2001a, 2001b), que a origem da contaminação fúngica nos packinghouses seja proveniente da fruta do campo. A composição e a freqüência 


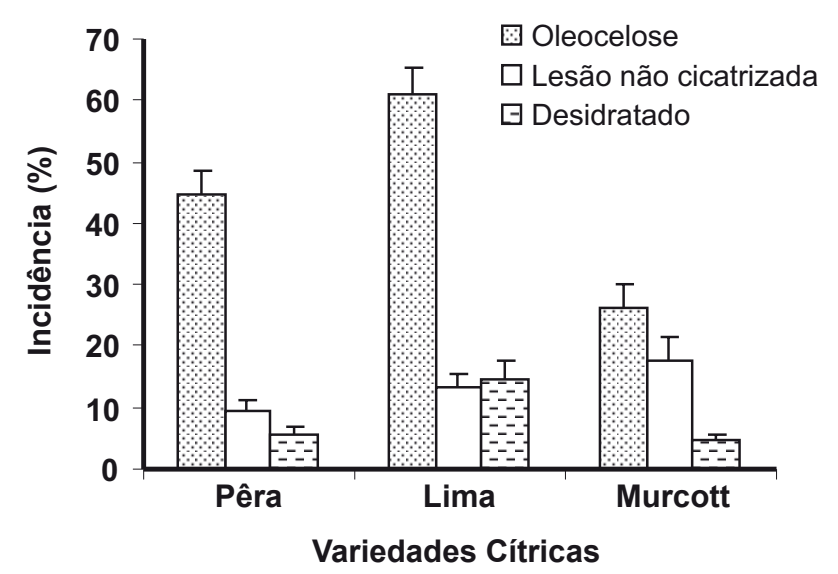

FIG. 1 - Incidência (\%) de injúrias abióticas em laranjas 'Pêra' e 'Lima' (maio a novembro de 2006) e em tangor 'Murcott' (agosto a novembro de 2006) avaliada em quatro atacadistas da Ceagesp SP. As barras representam o erropadrão da média.

TABELA 4 - Parâmetros físico-químicos $\left({ }^{\circ}\right.$ Brix e acidez) de frutos cítricos amostrados em 2006 na Ceagesp SP e seus coeficientes de correlação (r) com a incidência de bolor verde e total de podridões nos frutos

\begin{tabular}{lcccccc}
\hline \hline Variedade & ${ }^{\circ}$ Brix & $\begin{array}{c}\mathbf{r} \\
\left({ }^{\circ} \text { Brix/bolor) }\right.\end{array}$ & $\begin{array}{c}\mathbf{r} \\
\left({ }^{\circ} \text { Brix/total }\right. \\
\text { podr.) }\end{array}$ & $\begin{array}{c}\text { Acidez } \\
\mathbf{( \% )}\end{array}$ & $\begin{array}{c}\mathbf{r} \\
\text { (Acidez/bolor) }\end{array}$ & $\begin{array}{c}\mathbf{r} \\
\text { (Acidez/total } \\
\text { podr.) }\end{array}$ \\
\hline Pêra $^{1}$ & 9,28 & 0,21 & 0,75 & 0,77 & $-0,19$ & $-0,50$ \\
Lima $^{1}$ & 9,37 & $-0,88^{*}$ & $-0,97 *$ & 0,07 & 0,37 & 0,61 \\
Murcott $^{2}$ & 12,81 & 0,54 & 0,76 & 0,83 & $-0,07$ & $-0,69$ \\
\hline
\end{tabular}

* Significativo a 0,05 .

da micoflora dependem das condições locais de cada região (Palou et al., 2001a).

A micoflora total do ambiente, assim como a população de Penicillium, variou significativamente entre os meses amostrados $(P=0,0001)$, com médias entre 4,4 (agosto) e 38,7 ufc/placa de Petri (setembro) (Figura 2). Na Espanha, a micoflora total e a de Penicillium também apresentaram uma variabilidade elevada, com interações significativas entre épocas, packinghouses e pomares, e havendo uma correlação positiva entre a micoflora total e a temperatura ambiente $(\mathrm{r}>0,9)$ (Palou et al., 2001a, 2001b). Levantamentos comparativos entre verão e inverno paulista, em que os valores de temperatura e umidade relativa do ar são mais discrepantes, possivelmente permitiriam obter resultados mais conclusivos acerca do clima.

Correlação positiva $(\mathrm{r}=0,96$ e $P<0,05)$ entre a freqüência de $P$. digitatum encontrada no ambiente dos atacadistas (Figura 2) e o bolor verde em laranja 'Pêra' ali comercializada (Tabela 1), foi observada, entretanto, para laranja 'Lima' e tangor 'Murcott' tal correlação não foi verificada( $\mathrm{r}=0,25, P=0,63 \mathrm{er}=0,44, P=0,56$, respectivamente). Níveis de inóculo ambiental de Penicillium spp. e Botrytis cinerea em pomares e packinghouses de Pêra também não permitiram correlação com os índices de podridões (Lennox et al., 2003).
Embora a quantidade de inóculo fúngico influa decisivamente na incidência de doenças, outros fatores como a suscetibilidade intrínseca dos frutos a infecção e as condições ambientais antes e durante o período de colheita também apresentam importância, impossibilitando o estabelecimento de uma relação quantitativa entre os níveis de população fúngica na Ceagesp e os danos por podridões. Não existe para tanto, um critério geral que permita discernir quais os limites críticos de contaminação fúngica a partir dos quais existe um alto risco de ocorrer uma incidência de podridões inadmissível. Não obstante, procura-se definir, mediante os níveis fúngicos populacionais em packinghouses, zonas sujas e zonas limpas e também estabelecer limites críticos que permitam determinar a eficácia das operações de higienização (Gardner et al., 1986; Palou et al., 2001b). $\mathrm{O}$ conhecimento das áreas onde ocorrem os maiores níveis de contaminação permite adequar os programas de limpeza e desinfestação, e também pode resultar de grande interesse no desenho e adequação das infra-estruturas dos packinghouses (Gardner et al., 1986).

Com relação à higienização na Ceagesp, ela é feita por meio de varreções diárias e coleta dos resíduos orgânicos. Segundo Gardner et al. (1986), uma correta higienização é eficaz em reduzir a incidência de podridões, sendo mais eficiente economicamente que o incremento do uso de fungicidas. 


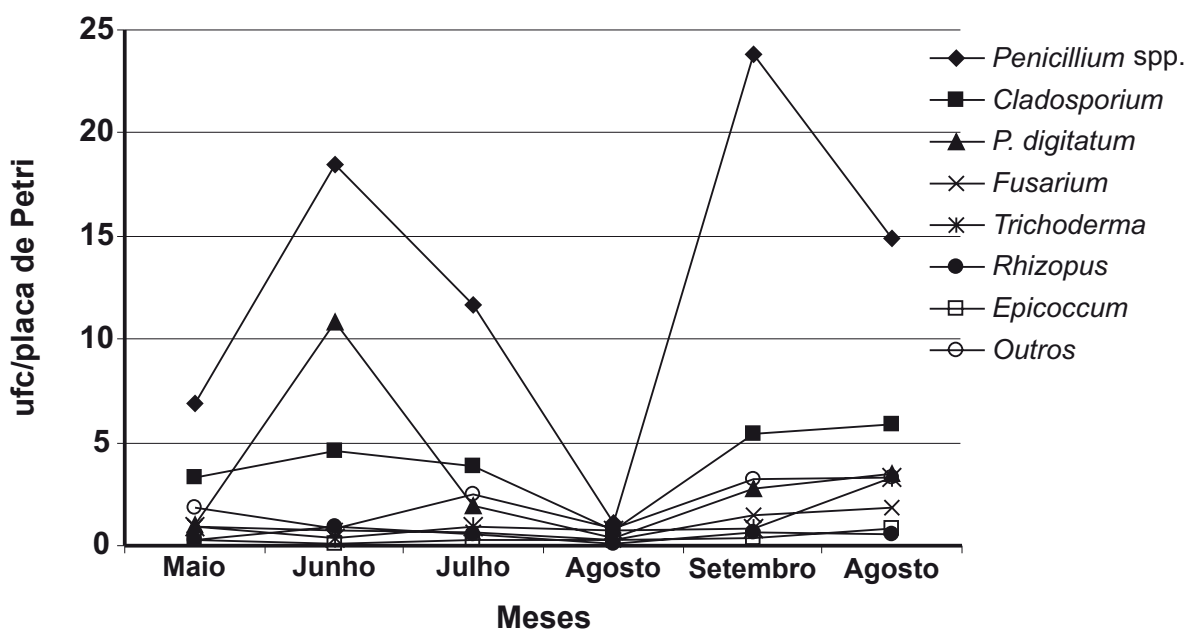

FIG. 2 - Freqüência de gêneros fúngicos isolados de ambiente de quatro atacadistas citrícolas na Ceagesp no período de maio a outubro de 2006.
Visando reduzir a ocorrência de podridões em frutos citricos, especialmente se o intuito for trabalhar em sistema de produção integrada, deve-se dar maior atenção ao manejo dos frutos em pós-colheita e a correta higienização da linha de beneficiamento (caixas de colheita, instalações, máquinas, câmaras, piso, etc.) e do ambiente de comercialização.

\section{AGRADECIMENTOS}

Os autores agradecem a Dra. Anita Gutierrez, Hélio S. Watanabe e Manoel da Silva Filho da Ceagesp SP pela colaboração na amostragem dos frutos cítricos.

\section{REFERÊNCIAS BIBLIOGRÁFICAS}

Barmore CR., Brown GE (1985) Influence of ethylene on increased susceptibility of oranges to Diplodia natalensis. Plant Disease 69:228-230.

Baudoin ABAM, Eckert JW (1982) Factors influencing the susceptibility of lemons to infection by Geotrichum candidum. Phytopathology 72:1592-1597.

Brown GE (1975) Factors affecting postharvest development of Colletotrichum gloeosporioides in citrus fruits. Phytopathology 65:404-409.

Carvalho CRL, Mantovani DMB, Carvalho PRN (1990) Análises químicas de alimentos: manual técnico do Instituto de Tecnologia de Alimentos. Campinas SP. Instituto de Tecnologia de Alimentos.

Dantas SAF, Oliveira SMA, Michereff SJ, Nascimento LC, Gurgel LMS, Pessoa WRLS (2003) Doenças fúngicas pós-colheita em mamões e laranjas comercializados na Central de Abastecimento do Recife. Fitopatologia Brasileira 28:528-533.

Eckert JW (1993) Post-harvest diseases of citrus fruits. Agriculture Outlook 54:225-232.

Eckert JW, Eaks IL (1989) Postharvest disorders and diseases of citrus fruits. In: Reuter W, Calavan EC, Carman GE (Eds.) The Citrus Industry. Vol. 5. Berkeley. University of California Press.

Gardner PD, Eckert JW, Baritelle JL, Bancroft MN (1986) Management strategies for control of Penicillium decay in lemon packinghouses: economic benefits. Crop Protection 5:26-32.

Ismail M, Zhang J (2004) Post-harvest citrus disease control. Outlooks on Pest Management 15:29-35.

Laranjeira FF, Amorim L, Bergamin Filho A, Aguilar-Vildoso CI, Della Colleta Filho H (2005) Fungos, procariotos e doenças abióticas. In: Mattos Junior D, De Negri JD, Pio RM, Pompeu Junior J (Eds.) Citros. Campinas SP. Instituto Agronômico e Fundag, Cap. 18, pp. 511-558.

Lennox CL, Spotts RA, Cervantes LA (2003) Populations of Botrytis cinerea and Penicillium spp. on pear fruit, and in orchards and packinghouses, and their relationship to postharvest decay. Plant Disease 87:679-644.

Mari M, Casalini L, Baraldi E, Bertolini P, Pratella GC (2003) Susceptibility of apricot and peach fruit to Monilinia laxa during phonological stages. Postharvest Biology and Technology 30:105109.

Medina CL, Rena AB, Siqueira DL, Machado EC (2005) Fisiologia dos citros. In: Mattos Junior D, De Negri JD, Pio RM, Pompeu Junior J (Eds.) Citros. Campinas SP. Instituto Agronômico e Fundag, Cap. 7, pp. 147-195.

Northover J, Biggs AR (1990) Susceptibility of immature and mature sweet and sour cherries to Monilinia fructicola. Plant Disease 74:280-284.

Palou L, Usall .J, Pons J, Viñas I (2001a) .Micoflora epifita de los frutos y ambiental en campos de mandarino 'Clemenules' en Tarragona. Revista Investigación Agraria: Production Protección Vegetal 16:257-272.

Palou L, Usall J, Pons J, Cerdà MC, Viñas I (2001b) Micoflora em centrales citrícolas de Tarragona. Revista Investigación Agraria: Production Protección Vegetal 16:447-462.

Pereira MEC, Cantillano FF, Gutierez ASD, Almeida GVB (2006) Procedimentos pós-colheita na produção integrada de citros. Cruz das Almas BA. Embrapa Mandioca e Fruticultura Tropical. 
Pio RM, Figueiredo JO, Stuchi ES, Cardoso SAB (2005) Variedades copas. In: Mattos Junior D, De Negri JD, Pio RM, Pompeu Junior J (Eds.) Citros. Campinas SP. Instituto Agronômico e Fundag. Cap. 3, pp. 37-60.

Ritenour MA, Pelosi RR, Burton MS, Stover EW, Dou H, Mccollum TG (2004) Assessing the efficacy of preharvest fungicide applications to control postharvest diseases of Florida citrus. Hortechnology 14:58-63.

Sharma RL, Kaul JL (1988) Susceptibility of apples to brown rot in relation to quantitative characters. Indian Phytopathology 43:113-115.

Souza DC (2007) Progresso temporal e padrão espacial de epidemias da podridão parda do pessegueiro. Dissertação de Mestrado. Piracicaba, SP. Universidade de São Paulo.

Timmer LW, Garnsey SM, Graham JH (2000) Compendium of Citrus Diseases. 2sd Ed. Saint Paul MN. APS Press.

Wild BL, Eckert JW (1982) Synergy between a benzimidazolesensitive isolate and benzimidazole-resistant isolates of Penicillium digitatum. Phytopathology 72:1329-1332.

Zadoks JC (1985) On the conceptual basis of crop loss assessment: the threshold theory. Annual Review of Phytopathology 23:455473.

Zar JH (1999) Biostatistical analyis. New Jersey. Prentice-Hall.

Recebido 11 fevereiro 2008 - Aceito 12 junho 2008 - TPP 7078

Editor Associado: Marciel J. Stadnik 